Epiphany: Vol. 7, No. 1, 2014

ISSN 1840-3719

\title{
Ethics and Dualism in Contemporary Psychology: From Avicenna and Descartes to Neuroscience
}

Alma Jeftić*

\begin{abstract}
From Avicenna and Descartes a long debate on the role of mind-body dilemma has left a huge impact on ethics of psychological research. That is especially applicable on researches that include both human and non-human participants, as well as their limitations and constraints that are connected to ethical principles. However, these principles are closely related to the interpretation of mind-body dilemma, which depends on different understandings of connection between soul and senses. The purpose of this paper is to examine the major impact of well-known "mind-body" dualism on ethics in psychological researches, with special emphasis on neuropsychology and neuroscience in general, as well as major constraints related to that dillema. The thought experiment has been recognized as a precursor to Rene Descartes' famous 'Cogito ergo sum', as well as his body-mind dilemma. However, Avicenna's argument is more intended to demonstrate conceptually that Aristotle's empirical axiom "there is nothing in the mind which was not first in the senses" is mistaken, since there is at least one thing in the mind which is not contingent upon experience, and that is self-awareness. The major contribution of this paper is the inclusion of two philosophical debates on mind-body dilemma while considering ethical approaches to neuropsychological research on both human and non-human participants.
\end{abstract}

Keywords: Ethics; Neuroscience; Dualism; Mind-body Dillema; Human and Non-human Participants

\footnotetext{
* Corresponding Author: Alma Jeftić, PhD Candidate, University of Belgrade; e-mail: ajeftic@ius.edu.ba 


\section{Introduction}

According to Avicenna theoretical psychology lies outside the province of the physician qua physician. In his experiment which he called the "flying man" or the 'floating' man, found at the beginning of his Fi'-Nafs/De Anima (Treatise on the Soul), he asks us to imagine a human being with absolutely no sensory experience. According to Avicenna's opinion, the only thing this person with no experiences would know is that she/he himself exists. Therefore, person would be aware of herself/himself (selfaware) quite apart from experiences of other things which stand in some relation to her/him.

The thought experiment has been recognized as a precursor to Rene Descartes' famous 'Cogito ergo sum', as well as his body-mind dilemma. However, Avicenna's argument is more intended to demonstrate conceptually that Aristotle's empirical axiom "there is nothing in the mind which was not first in the senses" is mistaken, since there is at least one thing in the mind which is not contingent upon experience, and that is selfawareness.

Suspended in such a state, person is not able to affirm the existence of her/his body because she/he is not empirically aware of it, thus the argument may be seen as affirming the independence of the soul from the body, a form of dualism. However, there is a subject that is thinking, so she/he cannot doubt that self exists therefore the argument can be seen as an 
affirmation of the self-awareness of the soul and its substantiality. This argument does raise an objection, which may be applicable to different understandings of ethics in neuroscientific research: how do we know that the knowing subject is the self and what the major differences and ethical constraints between human and nonhuman participants are.

\section{Avicenna's Psychology and Descartes' Dualism}

Avicenna's interest in classical psychology is primarily embodied in the Kitab al-nafs parts of his Kitab al-shifa' (The Book of Healing) and Kitab al-najat (The Book of Deliverance), which were known in Latin under the title De Anima. The main thesis of these tracts is represented in his "thought experiment", also known as "flying man" argument, which resonates with what was centuries later entailed by Descartes's cogito argument (Nader El-Bizri, 2003).

Avicenna's psychology requires that connection between the body and soul should be strong enough to ensure the soul's individuation, but weak enough to allow for its immortality (Rahman, 1981, 40). His psychology is based on physiology, which reveals that his understanding of the soul is one that deals almost entirely with the natural science of the body and its abilities of perception. Therefore, the major connection between the soul and body is explained by his understanding of perception,

\footnotetext{
Epiphany: Journal of Transdisciplinary Studies, Vol. 7. No. 1, (2014) ๑ Faculty of Arts and Social Sciences
} 
where bodily perception interrelates with the immaterial human intellect (Rahman, 1981, 40).

The perceiver senses the form of the object first by perceiving features of the object by our external senses, but sensory information is supplied to the internal senses, which merge all the pieces into a whole, unified conscious experience. This process of perception and abstraction is the nexus of the soul and body, for the material body may only perceive material objects, while the immaterial soul may only receive the immaterial, universal forms, therefore the soul and body interact in the final abstraction of the universal (Rahman, 1981, 41).

The soul completes the action of intellection by accepting forms that have been abstracted from matter, which means that a concrete particular (material) must be abstracted into the universal intelligible (immaterial) (Rahman, 1981, 68-69). Both of them continue interaction through the Active Intellect, which is a "divine light" containing the intelligible forms (Rahman, 1981, 68-69). Reason is designed material (or hylic), possible or habitual, and it may be called "material" either in the pure sense, by analogy with the pure matter, which in itself is entirely formless but is the substratum of all possible forms (Fakhry, 2004, $145)$.

The most lasting legacies of Descartes' philosophy are his thesis that mind and body are really distinct entities. That thesis is 
now called "mind-body dualism". He argues that the nature of the mind is completely different from that of the body, and therefore it is possible for one to exist without the other. This argument gives rise to some of the intriguing questions, such as: how can the mind cause some of our bodily limbs to move, and how can the body's sense organs cause sensations in the mind.

In the Second Meditation, Descartes argues that he is "thing that doubts, understands, affirms, denies, is willing, is unwilling, and also imagines and has sensory perceptions" (Descartes, 1985, 19). Neither a mind can be understood to be shaped or in motion, nor can a body understand or sense anything. However, human beings are combinations of mind and body such that the mind's choices can cause modes of motion in the body, and motions in certain bodily organs.

According to Descartes, a clear and distinct understanding of the mind without the body exists. Since the mind must have a surface and a capacity for motion, the mind must also be extended and, therefore, mind and body are not completely different. Even though he never described this problem clearly, Descartes himself never took this issue very seriously:

"These questions presuppose amongst other things an explanation of the union between the soul and the body, which I have not yet dealt with at all. But I will say, for your benefit at least, that the whole problem contained in such questions arises simply from a supposition that is false and cannot in any way be proved, namely that, if the soul and the body are two substances whose nature is different, this 
It is evident that his response to mind-body problem presupposes an explanation of the union between these two entities, as well as the false presupposition that two substances with completely different natures cannot act on each other.

\section{„Flying Man“6 vs ,Cogito“6}

One cannot fail to note the striking similarities between the flying man and Rene Descartes' cogito six centuries later (Kaukua, 2007, 14). Avicenna's most general definition of the soul conceives it as a perfection of a living body, but it is important to allow differences between the souls of animals and plants on the one hand, and the souls of human beings and the celestian spheres on the other hand (Kaukua, 2007, 24).

Avicenna's epistemology is based on a theory of soul that is independent of the body and capable of abstraction. This proof for the self in many ways prefigures by 600 years the Cartesian cogito and the modern philosophical notion of the self (Black, 2008, 65). It somehow demonstrates the Aristotelian base and Neoplatonic structure of his psychology. The so-called 'flying man' argument or thought experiment found at the beginning of his Fi'-Nafs/De Anima (Treatise on the Soul) can serve as one of the examples:

"We say: one of us must imagine himself as creates all at once an perfect but with his sight veiled from observing 
external things, and as created floating in the air or the void so that he would not encounter air resistance which he would have to sense, and with his limbs separate from each other in such a way that they neither meet nor touch each other. He must then reflect upon (the question) whether he would affirm the existence of his essence..." (Rahman 1959, 36)

The main question is: If a person were created in a perfect state, but blind and suspended in the air but unable to perceive anything through his senses, would he be able to affirm the existence of his self? Suspended in such a state, he cannot affirm the existence of his body because he is not empirically aware of it, thus the argument may be seen as affirming the independence of the soul from the body, which represents a form of dualism. But in that state he cannot doubt that his self exists because there is a subject that is thinking, thus the argument can be seen as an affirmation of the self-awareness of the soul and its substantiality (Black, 2008, 66). The same objection may also be posed at Descartes: how do we know that the knowing subject is the self?

This rational self possesses faculties or senses in a theory that begins with Aristotle and develops through Neoplatonism. According to Avicenna, the first sense is common sense, the second sense is imagination, the third sense is the imaginative faculty, the fourth sense is estimation, and the final sense is where the ideas produced are stored and analyzed and ascribed meanings based upon the production of the imaginative faculty and estimation (Fakhry, 2004). 
The last move in Avicenna's "Thought experiment" is slightly problematic, since it seems to contain the obviously fallacious inference pattern, "If I know x but I do not know y, then $x$ cannot be the same as $y$ " (Black, 2008, 11). The question of whether Avicenna explicitly or implicitly commits this fallacy, (which is often laid against the Cartesian cogito as well), has been much discussed. However, while the Flying Man argument focuses primarily on the impossibility that self-awareness is a mode of sense perception, the primitive character of the experience exemplified in the Flying Man poses parallel and equal difficulties for the claim that it could be a mode of intellectual understanding as well (Black 2008, 12).

\section{Ethics of Human Soul}

Avicenna's particular interest was in the persistence of the Soul's consciousness of itself and its identity throughout the changing cycle of psychic conditions and states, from dreaming to intoxication to sleep (Fakhry, 2004, 164). According to him, even if the Soul is supposed to have been suspended in the air, and without any contact with the body or the external world, it would still be fully unconscious of anything but the fact of its existence. By this fact, existence and identity are achieved at once.

The Soul itself is the basis, of the entire motive, cognitive or the vital functions we associate with it, and as such is logically prior to all these functions (Fakhry, 2004, 164). This concept is

\footnotetext{
Epiphany: Journal of Transdisciplinary Studies, Vol. 7. No. 1, (2014) @ Faculty of Arts and Social Sciences
} 
pretty similar to Descartes' cogito, and the similarity has been noted by many scholars. Also, both Aristotle and Plotinus had insisted on the unity or identity of the Soul and the fact that, in its inner and outer functions, motive and cognitive, it is diversified purely accidentally (Fakhry, 2004, 164).

Avicenna claims that human souls are subsistent entities in their own right, and yet, since there are multiple individuals in the species "human", those individuals can only been distinguished from one another by the diversity of their matter (Black, 2008, 77). But in that situation, what is happening to the souls of both human and non-human participants in neuropsychological researches? Is there possibility for researcher to distinguish causes and effects, or, to be sure that the knowing subject is aware? Are there difference between human and animal self-awareness, and, in the same line, differences in ethical principles that should be applied before conducting neuropsychological research on human and/or non-human participants?

According to the Ethical Principles of Psychologists and Code of Conduct (2010), "psychologist conducting intervention research involving the use of experimental treatments clarify to participants at the outset of the research (1) the experimental nature of the treatment; (2) the services that will or will not be available to the control group(s) if appropriate; (3) the means by which assignment to treatment and control groups will be made; (4) available treatment alternatives if an individual does not whish 
A. Jeftic Ethics and Dualism in Contemporary Psychology

to participate in the research or wishes to withdraw once a study has begun; and (5) compensation for or monetary costs of participating including, if appropriate, whether reimbursement from the participant or a third -party payor will be sought" (Standards 8.02b, Research and Publication, Informed Consent to Research).

However, there is no informed consent when it comes to the non-human participants, but the Ethical Principles of Psychologists and Code of Conduct (2010) contains parts describing "Human Care and Use of Animals in Research", as follows:

(a) Psychologists acquire, care for, use, and dispose of animals in compliance with current federal, state and local laws and regulations, and with professional standards.

(b) Psychologists trained in research methods and experienced in the care of laboratory animals supervise all procedures involving animals and are responsible for ensuring appropriate consideration of their comfort, health and humane treatment.

(c) Psychologists ensure that all individuals under their supervision who are using animals have received instruction in research methods and in the care, maintenance and handling of the species being used, to the extent appropriate to their role. 
A. Jeftic Ethics and Dualism in Contemporary Psychology

(d) Psychologists make reasonable efforts to minimize the discomfort, infection, illness and pain of animal subjects.

(e) Psychologists use a procedure subjecting animals to pain, stress or privation only when an alternative procedure is unavailable and the goal is justified by its prospective scientific, educational or applied value.

(f) Psychologists perform surgical procedures under appropriate anesthesia and follow techniques to avoid infection and minimize pain during and after surgery.

(g) When it is appropriate that an animal's life be terminated, psychologists proceed rapidly, with an effort to minimize pain and in accordance with accepted procedures.

However, it is evident that research ethics of non-human participants relies upon discomfort, illness, harms, while research ethics of human participants includes informed consent and basic information on research provided by researcher. Ethical standards do not include data on human and non-human souls, "knowing subject" and its ability to inform researcher of his/her/its states of awareness, as well as ethical considerations of interpretations of research results. It is a commonplace in the history of philosophy that issues surrounding self-awareness, consciousness, and selfknowledge do not become prominent until the early modern period, since for medieval philosophers, particularly those in the Aristotelian tradition, the nature of self-knowledge plays only an 177

Epiphany: Journal of Transdisciplinary Studies, Vol. 7. No. 1, (2014) @ Faculty of Arts and Social Sciences 
ancillary role in psychology and epistemology (Black, 2008, 63). This is a natural consequence of Aristotle's characterization of the intellect as a pure capacity that has no nature of its own, therefore self-knowledge for Aristotle is derivative upon knowledge of other things, and thought is itself thinkable in exactly the same way as its objects are (Black 2008, 64).

\section{States of Awareness: How Do We Know that the Knowing Subject Is the Self?}

Avicenna recognizes two distinct levels of self-knowledge, the most basic of which is exemplified in the experience of the Flying Man, which Deborah Black labeled "primitive selfawareness" (Black, 2008, 69). Primitive self-awareness violates many of the structures placed on self-knowledge by the Aristotelian principles, and Avicenna differentiates it from the reflexive awareness of oneself via one's awareness of an object that is characteristic of Aristotelianism (Black, 2008, 69). He also distinguishes primitive self-awareness from our knowledge of our bodies and psychological faculties and from our scientific understanding of our essential natures as humans; and he explicitly recognizes the capacity for "knowing that we know" as a distinctive form of self-knowledge (Black, 2008, 70).

It remains unclear whether Avicenna is able to provide a coherent account of the relations among primitive self-awareness and the other varieties of self-knowledge that he inherits from the 
Aristotelian tradition, but the broad contours of the Flying Man are generally well-known. Through that experiment, Avicenna identifies two fundamental sources of sense knowledge: everything previously acquired from experience, that is, all knowledge anchored in memory and imagination, and any ocurrent sensations (Black, 2008, 70).

Avicenna beliefs that no one would deny that his/her awareness of himself/herself would remain stable even in these conditions, therefore the subject would continue to affirm the existence of his self. Despite the fact that all sense perception is cut off, person is aware of his/her existence, and affirmation of our existence cannot be dependent upon the experience of having a body. Avicenna thus concludes that since "it is not possible for the thing of which one is aware and not aware to be one in any respect," it follows that the self cannot be either the whole body nor any one of its parts (Black, 2008, 74).

Insofar as the growth of the human body involves development of its faculties, and insofar as consequent changes in self-world relations are brought about through learning based on both exteroception and proprioception, these changes concern the corresponding dispositions in the intellect (Kaukua, 2007, 143). Corporeal awareness relies on perceptual functions (e.g., tactile, proprioceptive, gravitational, visual) and motor programs for bodily actions (Knoblich et al., 2006, 171). Also, picture of other people's bodies give rise to physical and emphatic responses in a 
way that no text can produce (Knoblich et al., 2006, 136). Experimental paradigms have proves useful in elucidating the neuropsychological mechanisms underlying phantom-limb experiences, especially for the hemiphantom or phantom halfbody (the experience of a defferented/deefferente half of one's body as an entity living a life on its own, and autoscopic phenomena in which one's entire body is experienced as a phantom (Knoblich et al., 2006, 172).

According to Avicenna, there are four basic requirements related to the concept of self-awareness: radical temporal continuity of self-awareness, non-reflectivity of self-awareness, immediacy of self-awareness, and lack of inherent objective content of self-awareness (Kaukua 2007, 102). However, Avicennian animals are capable of intentional apprehension of perceptible objects, therefore one can assume he is not denying the primitive type of self-awareness in animals (Kaukua, 2007, 112). If phenomenality is taken as a mental feature. then Descartes would have to deny any kind of awareness from animals and argues that animals can feel but that there is no sense of what it is like in this animal capacity of feeling (Morris 2000). However, difference between Avicenna and Descartes is quite obvious, and Avicennian animals are more "Aristotelian" animate beings.

If animals are primitively self-aware in much the same sense as humans, than it seems they should both adhere to the same ethical standards and guidelines prior to neuropsychological 
research. Since animals cannot provide informed consent, experiments should be organized in a way to include zero harm. However, interpretation of results and conclusions should be analyzed seriously, since one cannot be sure if the knowing subject(s) is(are) the Self. Whereas in humans the account of primitive self-awareness was most intimately connected to the individuated existence of the incorporeal human soul, this cannot be true of animals whose souls are material souls (Kaukua 2007, 114). However, there is no essential difference between animal and human self-awareness. The only difference that should be taken into account is that human self-awareness possesses capacity of taking itself as object of consideration (Kaukua 2007, 117).

\section{Conclusion}

The main purpose of this essay was to examine different approaches to human soul and self-awareness provided by Avicenna and Descartes in order to examine its influence on ethics of neuropsychological researches conducted on both human and non-human participants.

According to the ethical standards informed consent is necessary for human participants, while researches conducted on non-human participants should exclude harm and life-threatening situations (same is for human participants as well). However, differences between human and animal soul according to Avicennian psychology do not imply huge differences when it comes to ethical standards and guidelines for human and non- 
human participants. Since awareness is in its essence innate, knowing subject should be considered as a soul that is aware if its action in governing the body of both humans and non-humans. Therefore, the interpretation of neuropsychological experiments as well as results should be analyzed through the constraints of researcher to understand the dualism of mind and body united in self-awareness of knowing subject.

\section{References}

Black, Deborah. "Avicenna on Self-Awareness and Knowing that One Knows". The Unity of Science in Arabic Tradition. Logic, Epistemology, and the Unity of Science, Vol 11. Ed. Rahman, Shahid, Street, Tony, and Tahiri, Hassan. Kluwer Academic Publishers, 2008, 63-67.

Descartes, Rene. The Philosophical Writings of Descartes, 3 vols., (trans. John Cottingham, Robert Stoothoff, Dugald Murdoch and Anthony Kenny). Cambridge: Cambridge University Press, 1984-1991.

El-Bizri, Nader. "Avicenna's De Anima between Aristotle and Husserl". The Passions of the Soul in the Metamorphosis of Becoming. Ed. AnnaTeresa Tymieniecka. Dordrecht: Kluwer Academic Publishers, 2003, 67-89.

Ethical Principles of Psychologists and Code of Conduct. Adopted August 21, 2002; Effective June 1, 2003. With the 2010 Amendments. American Psychological Association.

Fakhry, Majid. A History of Islamic Philosophy. New York: Columbia University Press, 2004.

Kaukua, Jari. Avicenna on Subjectivity. A Philosophical Study. Yivaskyla: University of Yivaskyla, 2007.

Knoblich, Gunther, Thornton, Ian M., Grosjean, Marc, and Shiffrar, Maggie. Human Body Perception from Inside Out. London: Oxford University Press, 2006.

Morris, Katherine. "Bethes machines". Descartes Natural Philosophy. Ed. Gaukroger, Stephen et al. London: Routledge, 2000, 401-419.

Rahman, F. Avicenna's Psychology. An English translation of Kitāb al-Najāt, Book II, Chapter VI, with Historico-Philosophical Notes and Textual Improvements on the Cairo edition. London: Oxford University Press, 1981. 